
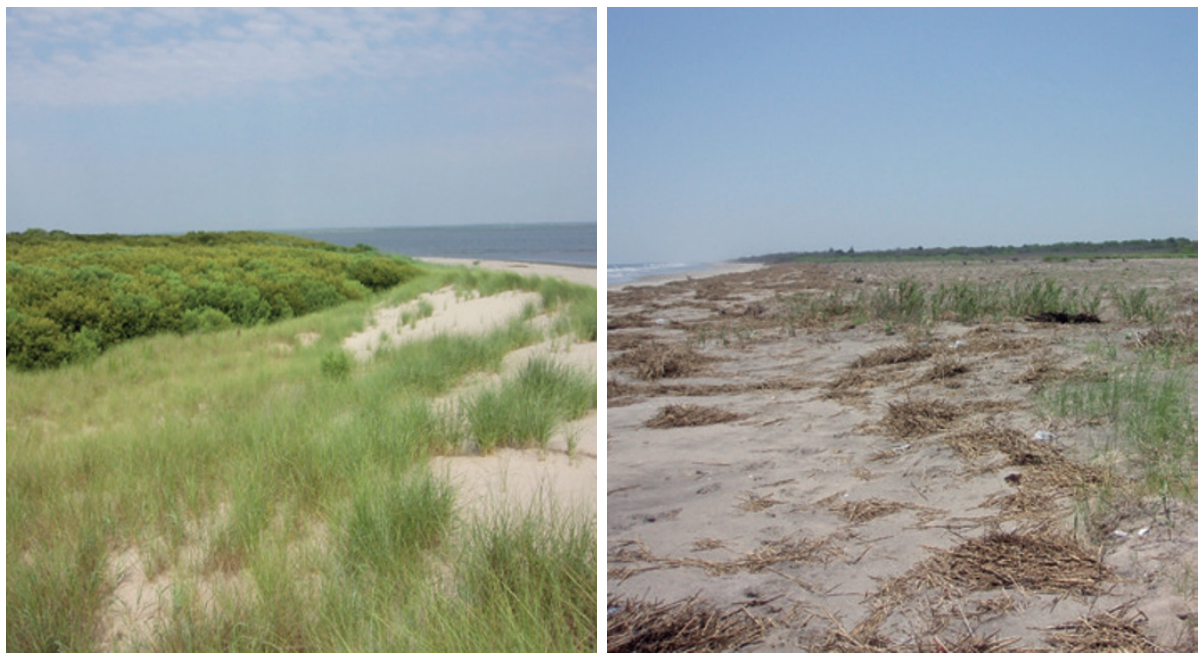

Figure 1 | Images of Hog Island showing that both states exist within a single island. Left: stable high-elevation vegetated dunes backed by extensive woody vegetation on the north end of the island $\left(37^{\circ} 27^{\prime} 43^{\prime \prime} \mathrm{N}, 75^{\circ} 39^{\prime} 58^{\prime \prime} \mathrm{W}\right)$. Right: large low-elevation overwash fan that bisects the island $<3 \mathrm{~km}$ away from the location depicted in the left panel $\left(3^{\circ} 26^{\prime} 18^{\prime \prime} \mathrm{N}, 75^{\circ} 40^{\prime} 09^{\prime \prime} \mathrm{W}\right)$. Images courtesy of S. Brantley.

states $^{6}$ (Fig. 1). Until recently, the southern portion of the island was dominated by extensive overwash and was eroding at more than $5 \mathrm{~m} \mathrm{yr}^{-1}$ (refs 5,6). Despite this low-elevation state, the northern portion of the island was accreting seaward at rates of $>5 \mathrm{~m} \mathrm{yr}^{-1}$ (ref. 5) with woody vegetation expanding into the southern portion of the island ${ }^{4,7}$. Similarly, Smith Island, which was also characterized as a low-elevation island (see figure 1 in ref. 1 , $\sim 90 \mathrm{~km}$ alongshore distance), has a strong bimodal distribution in elevation and one of the most diverse plant assemblages on the Virginia Barrier Islands due to the evolution of shore-perpendicular dune ridges, island width, human land-use and close proximity to mainland seed sources ${ }^{8,9}$. The southern portion of the island contains primary dune ridges that are 1-2 $\mathrm{m}$ in elevation, whereas the elongated northern portion is highly variable and exhibits signs of rollover with exposed peat outcrops in some locations?. These examples show that bistability operates at the local level on barrier islands and a single island may consist of a mosaic of alternate states $^{10}$. Therefore, the application of the published models ${ }^{1}$ at the island level for coastal management decision-making is not supported by the islands of the Virginia Coast Reserve. However, these models are a valuable contribution to understanding of local-scale processes.

\section{References}

1. Dúran Vinent, O. \& Moore, L. J. Nature Clim. Change 5, 158-162 (2015).

2. Beisner, B. E., Haydon, D. T. \& Cuddington, K. Front. Ecol. Environ. 1, 376-382 (2003).

3. Hayden, B. P., Santos, M. C. F. V., Shao, G. \& Kochel, R. C Geomorphology 13, 283-300 (1995).

4. Young, D. R. et al. Ecosystems 10, 854-863 (2007).

5. Brantley, S. T. et al. PLoS ONE 9, e104747 (2014).

6. Hayden, B. P., Dueser, R. D., Callahan, J. T. \& Shugart, H. H. Bioscience 41, 310-318 (1991).

7. Zinnert, J. C., Shiflett, S. A., Vick, J. K. \& Young, D. R. Geocarto Int. 26, 595-612 (2011)

8. Clovis, J. F. Castanea 33, 115-121 (1968).

9. Bachmann, C. M. et al. IEEE Trans. Geosci. Remote Sens. 40, 2313-2330 (2002).

10. Stallins, J. A. Ecol. Complex. 2, 410-430 (2005).

\section{Julie C Zinnert ${ }^{1 \star}$, Steven T Brantley ${ }^{2}$ and}

Donald R Young

'Department of Biology, Virginia

Commonwealth University, 1000 West Cary

Street, Richmond, Virginia 23284, USA.

2Joseph W. Jones Ecological Research

Center, 3988 Jones Center Drive, Newton,

Georgia 39870, USA.

*e-mail: jczinnert@vcu.edu

\title{
Reply to 'Bistability and the future of barrier islands'
}

\section{Durán Vinent and Moore reply - We} thank Zinnert et al. ${ }^{1}$ for the opportunity to elaborate further on the local nature of the bistability (that is, the tendency for islands to exist in alternate states under a given set of conditions) indicated by our numerical results ${ }^{2}$. Because our model assumes uniform alongshore conditions (that is, does not consider alongshore variability) all of our conclusions apply strictly to the local barrier island elevation. In particular, the bistability of local island elevation is supported by the bimodal distribution of dune elevation along the Virginia Barrier Islands (figure 1e,f in ref. 2). Examples shown in figure 1a-d in ref. 2 correspond to sections of the island in a high or low elevation state, where we use the implicit convention of naming an island high (low) if its average elevation is above (below) the crossover elevation defined in figure 1f. Although a detailed analysis of the spatial dynamics is beyond the scope of this work, there are two fundamental spatial scales suggested by our model ${ }^{2}$ that are important in determining future barrier island state: the scale of the spatial variation of the vulnerability index (eq. (1) of ref. 2), which is the control parameter that determines whether island elevation is bistable and that quantifies the probability of dune recovery (figures $3 e$ and 4 in ref. 2); and the spatial scale of alongshore variations in extreme water levels that erode dunes and drive a transition from a high to a low state. The stochastic alongshore variation of storm-induced erosion implies that both states can coexist spatially in a bistable system and at different scales, for example, at the scale of individual islands or at the scale of island segments, as observations suggest is the case for the Virginia Barrier Islands. In summary, because alongshore variability in processes and through history may prevent entire islands from existing in the low or high state, our concept of bistability applies most strictly to individual points or local sections of a barrier island.

References

1. Zinnert, J. C., Brantley, S. T. \& Young, D. R. Nature Clim. Change 6, 5-6 (2016).

2. Dúran Vinent, O. \& Moore, L. J. Nature Clim. Change 5, 158-162 (2015).

Orencio Durán Vinent' and Laura J. Moore 2 'MARUM Center for Marine Environmental Sciences, University of Bremen, Leobener Strasse, D-28359 Bremen, Germany. ${ }^{2}$ Department of Geological Sciences, University of North Carolina, 104 South Road, Mitchell Hall, Campus Box 3315, Chapel Hill, North Carolina 27599, USA. e-mail: oduran@marum.de; laura.moore@unc.edu 